\title{
Editorial: Richard A. Brand MD, Editor-in-Chief 2002-2012
}

\author{
Randall E. Marcus MD, Lee Beadling BA
}

Published online: 20 October 2012

(C) The Association of Bone and Joint Surgeons (B) 2012

Richard A. Brand has served as the Editor-in-Chief of Clinical Orthopaedics and Related Research ${ }^{\circledR}\left(\mathrm{CORR}^{\circledR}\right)$ for the last 10 years. When he took the helm in 2002, CORR was already an internationally renowned orthopaedic journal, with a stellar half-century reputation. Under his leadership, it has become one of the most highly quoted and cited orthopaedic journals in the world with more than twothirds of CORR article downloads occurring outside of North America. During his leadership, the editorial office has evolved from receiving typewriter-produced and postal-mailed manuscripts to a completely paperless environment with electronic submission, acceptance and production processes. His term as Editor has seen communication with authors go from telephone calls, faxes and overnight packages to email, tweets on Twitter and Facebook postings. In 2002, when Dr. Brand's tenure began as our Editor-in-Chief, the journal's impact factor was 1.2, and due in part to his insistence on high-quality research that measure has more than doubled to 2.5 in 2011. In 2002, the average time from submission to publication for a manuscript was 386 days and by the end of 2011, the average time from submission to publication was nearly cut by half to 186 days. Submissions to CORR have increased from 882 in 2002 to 1,600 per year. Individually these are incredible achievements in this age of the complexities and competition involved in medical publishing; considering

R. E. Marcus $(\bowtie)$

Department of Orthopaedic Surgery, Case Western Reserve

University, University Hospitals Case Medical Center,

11100 Euclid Avenue, Cleveland, OH 44106, USA

e-mail: randall.marcus@uhhs.com

L. Beadling

Clinical Orthopaedics and Related Research, 1600 Spruce Street,

Philadelphia, PA 19103, USA they all occurred in such a short time span is a testament to Dr. Brand's talent, determination and devotion to this journal.

Dr. Brand has made an indelible mark on our profession and his efforts have improved patient care for musculoskeletal conditions worldwide. He has been a mentor and friend to many in our profession and his attention to detail has greatly improved our scientific writing and transformed surgeons into scientific writers-never an easy feat!

Richard A. Brand has earned a place in the "hall of fame" of our profession, alongside our very best surgeons, including his predecessors as Editors-in-Chief of CORR: Anthony DePalma, Marshall Urist, and Carl Brighton. This recognition is not just for his many scientific contributions or just for his leadership in medical publishing but for his time, commitment, and personal input into every manuscript published in CORR during the last decade. He made each of us look better than we deserve! Perhaps the famous editor Betsy Lerner said it best when she noted her reaction to an editor revising her work, "It was a miracle, this transformation of my acorns into oaks" [1].

On behalf of all of us in the Association of Bone and Joint Surgeons ${ }^{\circledR}$, the CORR Board of Trustees, as well as your many readers across the world, Dr. Brand you have our sincere thanks and very best wishes for your welldeserved retirement.

\section{Reference}

1. Lerner B. The Forest for the Trees: An Editor's Advice to Writers. New York, NY: Riverhead Books; 2000. 